\title{
Carpal tunnel syndrome in acromegaly: a nationwide study
}

\section{Konstantina Vouzouneraki ${ }^{1}$, Daniela Esposito2,3, Sebastian Mukka ${ }^{4}$, Daniel Granfeldt ${ }^{5}$, Oskar Ragnarsson ${ }^{2,3}$, Per Dahlqvist' ${ }^{1}$ and Daniel S Olsson ${ }^{2,3}$}

${ }^{1}$ Department of Public Health and Clinical Medicine, Umeå University, Umeå, Sweden, ${ }^{2}$ Department of Endocrinology, Sahlgrenska University Hospital, Gothenburg, Sweden, ${ }^{3}$ Department of Internal Medicine and Clinical Nutrition, Institute of Medicine, Sahlgrenska Academy, University of Gothenburg, Gothenburg, Sweden, ${ }^{4}$ Department of Surgical and Perioperative Sciences, Umeå University, Umeå, Sweden, and ${ }^{5}$ PharmaLex, Gothenburg, Sweden
Correspondence should be addressed to K Vouzouneraki Email

konstantina.vouzouneraki@ umu.se

\begin{abstract}
Objective: Carpal tunnel syndrome (CTS) is common in patients with acromegaly, with a reported prevalence of 19-64\%. We studied CTS in a large national cohort of patients with acromegaly and the temporal relationship between the two diagnoses.

Design: Retrospective, nationwide, cohort study including patients diagnosed with acromegaly in Sweden, 2005-2017, identified in the Swedish Healthcare Registries.

Methods: CTS (diagnosis and surgery in specialised healthcare) was analysed from 8.5 years before the diagnosis of acromegaly until death or end of the study. Standardised incidence ratios (SIRs) with 95\% Cls were calculated for CTS with the Swedish population as reference.

Results: The analysis included 556 patients with acromegaly (50\% women) diagnosed at mean (s.D.) age 50.1 (15.0) years. During the study period, 48 patients were diagnosed with CTS and 41 patients underwent at least one CTS surgery. In the latter group, 35 (85\%) were operated for CTS before the acromegaly diagnosis; mean interval (range) $2.2(0.3-8.5)$ years and the SIR for having CTS surgery before the diagnosis of acromegaly was 6.6 (4.8-8.9). Women with acromegaly had a higher risk for CTS than men (hazard ratio: $2.5,95 \%$ Cl: 1.3-4.7).

Conclusions: Patients with acromegaly had a 6-fold higher incidence for CTS surgery before the diagnosis of acromegaly compared with the general population. The majority of patients with both diagnoses were diagnosed with CTS prior to acromegaly. Increased awareness of signs of acromegaly in patients with CTS might help to shorten the diagnostic delay in acromegaly, especially in women.
\end{abstract}

\section{Introduction}

Acromegaly is a rare disease, with an annual incidence of $3-4$ cases per million. It is characterised by excess secretion of growth hormone (GH), usually caused by a pituitary adenoma $(1,2)$. Acromegaly is associated with excess mortality and several comorbidities such as type 2 diabetes, cardiovascular disease, arthropathy, sleep apnoea and carpal tunnel syndrome (CTS) $(3,4,5,6,7$, 8). Unfortunately, there is still a considerable diagnostic delay for patients with acromegaly, which may hamper the (c) 2021 European Society of Endocrinology Printed in Great Britain possibilities for radical tumour resection and contribute to increased morbidity, mortality and impaired quality of life $(9,10,11,12,13)$. Recent clinical guidelines emphasise the importance of early diagnosis and treatment of acromegaly and its related comorbidities (14).

CTS is the most common peripheral compression neuropathy in the general population, with an estimated prevalence of $3-5 \%,(15,16)$. Female gender, age, diabetes mellitus, rheumatoid arthritis and previous trauma are 
known risk factors for CTS in the general population (16, 17). CTS is caused by compression of the median nerve as it passes through the carpal tunnel of the wrist, resulting in venous congestion and ischaemic damage to the nerve (16). Median nerve compression leads to intermittent paraesthesia, loss of sensation and, sometimes, pain and motor impairment in the hand (16, 18). Surgical decompression of the median nerve is the most effective treatment for CTS (16).

Small studies, with fewer than 60 patients, and various diagnostic criteria of CTS have suggested a high but variable prevalence of CTS in patients with acromegaly (19-64\%) $(19,20,21,22)$. A large registry study analysing data reported by physicians showed that $18 \%$ of the patients with acromegaly had a history of CTS (23). Electrophysiological and imaging studies in small cohorts of patients with acromegaly ( $<50$ patients) indicate variable frequencies of nerve conduction delay (42-81\%) and enlarged median nerves, possibly due to oedema $(19,20,22,24,25)$. Large studies on the excess risk of clinically significant CTS in patients with acromegaly compared with the general population and the temporal relationship between these diagnoses are lacking.

The aim of this study was to investigate the incidence of CTS in a large, nationwide, unselected cohort of patients with acromegaly compared with the general population. Secondary aims were to identify potential risk factors for CTS in patients with acromegaly and to analyse the temporal relationship between the diagnoses.

\section{Patients and methods}

\section{Study setting and registries}

We performed a national registry-based, retrospective cohort study. Patients with acromegaly were identified in the Swedish National Patient Registry (Patient Registry), which contains information on patients admitted to hospitals (since 1987) and outpatient day-surgery (since 1997) (26). Data on medical treatment were collected from the Swedish Prescribed Drug Registry, which contains information on all prescribed drugs in Sweden since 1 July 2005 (27). Information about time of death was obtained from the Swedish National Cause of Death Registry, which collects information on every death in Sweden since 1961. The unique Swedish personal identity number assigned to each Swedish resident allows linkage between population and health data registries.
The registries are held by the National Board of Health and Welfare that secures a high quality and coverage (26). All diagnostic codes refer to the 10th version of the International Classification of Diseases (ICD-10). All procedure codes refer to the Swedish Classification of Health Interventions (28).

\section{Data collection}

All adult patients in the Patient Registry receiving their first diagnosis of acromegaly (E22.0) between 1 July 2005 and 31 December 2017 combined with a diagnosis of pituitary tumour (D35.2 or D44.3) up to 5 years before or any time after the first diagnosis of acromegaly were included in the study. We investigated the incidence of CTS diagnosis defined as the presence of G56.0 (CTS) or O26.8D (CTS during pregnancy) code as the main diagnosis from 8.5 years before the diagnosis of acromegaly (index date) until death or end of the study (31 December 2017). We also investigated the incidence of surgical decompression of the median nerve (ACC51) during the same period of time. Data on acromegaly treatments including medical therapy, surgical treatment and radiotherapy were obtained from the Patient Registry and the Drug Registry. Data on potential risk factors for CTS among acromegaly patients such as age, gender, age at acromegaly diagnosis, hypopituitarism, diabetes mellitus and rheumatoid arthritis were acquired from the Patient Registry (diagnosis and treatments codes are shown in Supplementary Table 1 , see section on supplementary materials given at the end of this article). Start date for the inclusion of patients was set to 1 July 2005 in order to investigate a period of time when data were available from all registries. The time window was set to 8.5 years in order to investigate a period of time when data on surgery at outpatient visits were available from the Patient Registry for all patients, that is, 1 January 1997.

\section{Ethics}

The study was approved by the Regional Ethical Review Board in Gothenburg, Sweden (registration number 82014) and by the National Board of Health and Welfare, Sweden.

\section{Statistical analysis}

Continuous variables are presented as means ( \pm S.D.) and categorical variables as numbers (\%). We identified the date of acromegaly diagnosis and CTS (first diagnosis and 
Table 1 Demographic and clinical characteristics of the whole study cohort and in those with carpal tunnel syndrome diagnosis and surgery, respectively.

\begin{tabular}{|c|c|c|c|}
\hline & Total $(n=556)$ & CTS diagnosis $(n=48)$ & CTS surgery $(n=41)$ \\
\hline Age at acromegaly diagnosis, years, mean (s.D.) & $50.1(15.0)$ & $49.3(12.0)$ & $48.7(11.7)$ \\
\hline \multicolumn{4}{|l|}{ Gender, $n(\%)$} \\
\hline Male & $278(50)$ & $14(29)$ & $11(27)$ \\
\hline Female & $278(50)$ & $34(71)$ & $30(73)$ \\
\hline \multicolumn{4}{|l|}{ Comorbidities, $n(\%)$} \\
\hline Diabetes mellitus & $91(16)$ & $9(19)$ & $7(17)$ \\
\hline Rheumatoid arthritis & $7(1.3)$ & 0 & 0 \\
\hline Hypopituitarism & $139(25)$ & $16(33)$ & $13(32)$ \\
\hline \multicolumn{4}{|l|}{ Treatment for acromegaly, $n$ (\%) } \\
\hline Pituitary surgery & $407(73)$ & $45(94)$ & $38(93)$ \\
\hline Pituitary radiotherapy & $76(14)$ & $8(17)$ & $6(15)$ \\
\hline Surgery and radiotherapy & $72(13)$ & $8(17)$ & $6(15)$ \\
\hline Somatostatin analogue & $195(35)$ & $19(40)$ & $14(34)$ \\
\hline Pegvisomant & $51(9.2)$ & $5(10)$ & $5(12)$ \\
\hline Dopamine agonist & $125(23)$ & $10(21)$ & $9(22)$ \\
\hline
\end{tabular}

CTS, carpal tunnel syndrome.

all surgeries), respectively, in patients with both diagnoses in order to study which diagnosis was set first and the time period between them. Standardised incidence ratio (SIR) for CTS diagnosis was calculated for the first event of CTS diagnosis. SIR for CTS surgery was calculated on an annual basis (one patient could contribute a maximum of one surgery per calendar year). Person-years at risk were calculated from index date to death, an event (for CTS diagnosis) or end of study, and stratified according to gender, 5-year age groups and 1-year calendar periods. SIR was also calculated separately for the periods before and after diagnosis of acromegaly, with person-years at risk from index date to acromegaly diagnosis or an event, and from the diagnosis of acromegaly to an event, death or end of the study, respectively. The expected number of events for each stratum was calculated by using the general Swedish population for every calendar year and 5 -year age group as reference. The observed number of events among the acromegaly cohort was compared with the expected number from the general population and is presented as SIRs with 95\% CIs. Ninety-five percent CIs were calculated assuming a Poisson distribution of the observed numbers. SIRs were also calculated for subgroups of men and women, and for patients with and without diabetes. In order to identify potential risk factors for CTS, both univariate and multivariate Cox regression analyses of the time to CTS diagnosis and the time to CTS surgery were performed with age at diagnosis of acromegaly, gender and diabetes mellitus as covariates. All statistical analyses were performed in SAS version 9.4 (SAS Institute, Cary, NC).

\section{Results}

\section{Patient characteristics}

The study included 556 patients (278 men, 278 women) with acromegaly diagnosed between January 1997 and December 2017, and mean (s.D.) age at diagnosis of 50.1 (15.0) years (Table 1). The total follow-up time was 8020 person-years. During the whole study period 48 (8.6\%) of the patients (34 (70\%) women) were diagnosed with CTS at specialised health care facilities $(92 \%$ at orthopaedic or hand surgery departments). Forty-two patients (7.6\%) were diagnosed with CTS during the 8.5 years before the acromegaly diagnosis. Surgical decompression of the median nerve was performed in 41 (7.4\%) patients, of which $35(6.3 \%)$ had their surgery performed during the 8.5 years before the acromegaly diagnosis. Among the patients operated for CTS, 20 underwent one surgery, 20 underwent two surgeries and one patient underwent four decompression surgeries. Median (range) time between the first and second surgical procedure was 3.9 (0.7-77) months. Ninety-four percent of the patients with CTS diagnosis were treated with pituitary surgery compared with $72 \%$ of patients without CTS diagnosis. Among patients with multiple pituitary surgeries, 30\% had undergone one CTS surgery but none of them had undergone multiple CTS surgeries (Supplementary Table 2).

\section{Temporal relation of CTS and acromegaly diagnosis}

In 42 of 48 (88\%) patients with acromegaly and CTS, median (range) time to first CTS diagnosis was 3.1 
(0.3-8.5) years before the acromegaly diagnosis (Supplementary Fig. 1). Similarly, 35 of 41 (85\%) patients operated for CTS underwent CTS surgery before being diagnosed with acromegaly: median (range) time 2.2 (0.38.5) years (Fig. 1).

\section{Standardised incidence ratio of CTS in patients with acromegaly}

During the whole study period, the SIR for CTS diagnosis was 3.8 (95\% CI: 2.8-5.0; $P<0.0001)$ and the SIR for CTS surgery was 4.2 (95\% CI: 3.1-5.4).

During the 8.5-year period before the diagnosis of acromegaly, the SIR for the first CTS diagnosis was 5.9 (95\% CI: 4.2-7.9; $P<0.0001$ ), with similar excess risk for men (SIR: 5.4, 95\% CI: 2.8-9.4) and women (SIR: 6.1, 95\% CI: 4.1-8.7) (Table 2). Similarly, SIR for CTS in acromegaly patients was not different in patients with and without diabetes mellitus (Table 2).

The incidence of decompression surgery for CTS in patients with acromegaly was also significantly increased before the diagnosis of acromegaly (SIR: 6.6, 95\% CI: 4.8-8.9), with similar excess risk for men (SIR: 5.4, 95\% CI: 2.7-9.7) and women (SIR: 7.1, 95\% CI: 4.9-10.0] for women) (Table 2). After the diagnosis of acromegaly, SIRs for CTS diagnosis and surgery were 1.1 (95\% CI: 0.4-2.4) and 1.5 (95\% CI: 0.7-2.8), respectively.

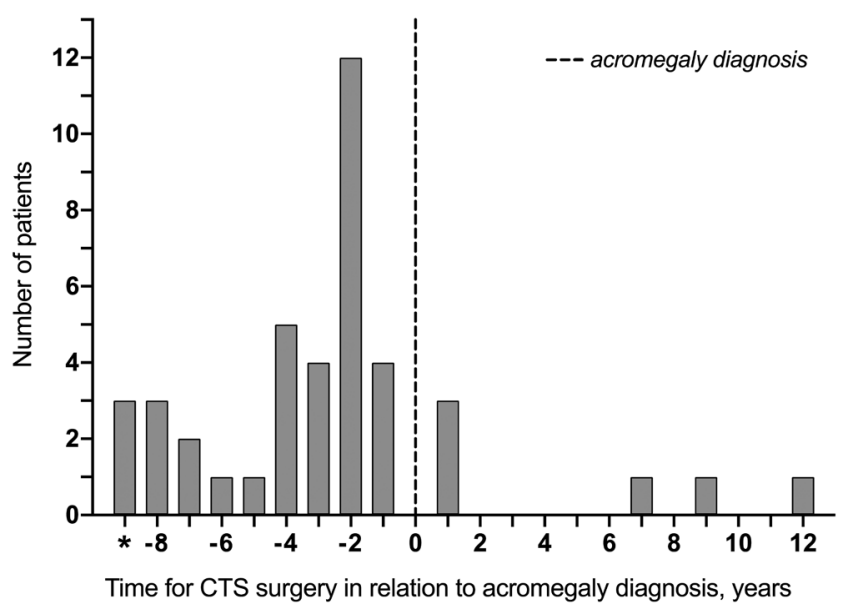

Figure 1

Time of the first carpal tunnel syndrome (CTS) surgery $(n=41)$ in relation to acromegaly diagnosis. *Illustrates a 6-month time period (8-8.5 years prior to acromegaly diagnosis).

\section{Risk factors for CTS in acromegaly}

In univariate Cox regression analysis, female gender was associated with increased risk of CTS diagnosis (hazard ratio (HR): $2.5,95 \% \mathrm{CI}: 1.3-4.7 ; P=0.0038$ ) and CTS surgery (HR: 2.8, 95\% CI: $1.4-5.6 ; P=0.0034$ ). The effect of gender on the risk of CTS diagnosis and CTS surgery remained significant in multivariable Cox regression analysis including the non-significant factors of diabetes mellitus and age at acromegaly diagnosis as covariates (data not shown). Rheumatoid arthritis was not included in the Cox regression analysis due to the low number of patients affected $(n=7)$.

\section{Discussion}

In this nationwide study, we found that both the incidence of CTS diagnosis and surgical treatment of CTS before the diagnosis of acromegaly were increased sixfold compared with the general population. More than eight out of ten patients with acromegaly and CTS were diagnosed and surgically treated for CTS prior to the diagnosis of acromegaly, with a median interval of 3 years between the two diagnoses. Among acromegaly patients, the risk for CTS was almost three-times higher in women than in men, whereas other known risk factors for CTS were not found to affect the risk for CTS in patients with acromegaly.

To our knowledge, this is the first nationwide study focusing on the temporal relationship between acromegaly and CTS. Considering the long diagnostic delay with excess $\mathrm{GH}$ exposure for years before the diagnosis of acromegaly, it is crucial to investigate the incidence of CTS during a long period before the diagnosis of acromegaly $(9,13)$. More than eight of ten acromegaly patients with CTS were diagnosed and operated for CTS prior to their acromegaly diagnosis. This finding highlights the opportunity to shorten diagnostic delay for acromegaly with an increased awareness of possible acromegaly in patients with CTS. Previous retrospective, questionnaire-based studies have shown that a majority of patients with acromegaly report CTS symptoms on average 6 years before the diagnosis of acromegaly and that $5-17 \%$ of patients have undergone CTS surgery prior to the diagnosis of acromegaly $(9,21,29)$. In the current study, analysis of the temporal relation between CTS and acromegaly was instead based on objective data retrieved from Swedish national health registries in a large, unselected cohort. 
Table 2 Standardised incidence ratio for carpal tunnel syndrome diagnosis and decompression surgery in patients with acromegaly presented for the time periods prior to and after the diagnosis of acromegaly.

\begin{tabular}{|c|c|c|c|c|}
\hline & Observed events & Expected events & SIR $(95 \% \mathrm{Cl})$ & $P$-value \\
\hline \multicolumn{5}{|c|}{ CTS diagnosis prior to acromegaly diagnosis } \\
\hline Total & 42 & 7.2 & $5.9(4.2-7.9)$ & $<0.0001$ \\
\hline Men & 12 & 2.2 & $5.4(2.8-9.4)$ & $<0.0001$ \\
\hline Women & 30 & 4.9 & $6.1(4.1-8.7)$ & $<0.0001$ \\
\hline With diabetes mellitus & 6 & 1.4 & $4.2(1.5-9.1)$ & 0.0073 \\
\hline Without diabetes mellitus & 36 & 5.7 & $6.3(4.4-8.7)$ & $<0.0001$ \\
\hline \multicolumn{5}{|c|}{ CTS surgery prior to acromegaly diagnosis } \\
\hline Total & 44 & 6.7 & $6.6(4.8-8.9)$ & $<0.0001$ \\
\hline Men & 11 & 2.0 & $5.4(2.7-9.7)$ & $<0.0001$ \\
\hline Women & 33 & 4.7 & $7.1(4.9-10.0)$ & $<0.0001$ \\
\hline With diabetes mellitus & 4 & 1.3 & $3.0(0.8-7.8)$ & 0.090 \\
\hline Without diabetes mellitus & 40 & 5.4 & $7.5(5.3-10.2)$ & $<0.0001$ \\
\hline \multicolumn{5}{|c|}{ CTS diagnosis after acromegaly diagnosis } \\
\hline Total & 6 & 5.5 & $1.1(0.4-2.4)$ & 0.95 \\
\hline \multicolumn{5}{|c|}{ CTS surgery after acromegaly diagnosis } \\
\hline Total & 9 & 6.0 & $1.5(0.7-2.8)$ & 0.31 \\
\hline
\end{tabular}

Subgroups categorised by gender and the presence of diabetes mellitus for the time period before the acromegaly diagnosis. Only the first CTS diagnosis was analysed. Each patient could contribute a maximum of one surgery (event) per calendar year.

CTS, carpal tunnel syndrome; SIR, standardised incidence ratio.

Acromegaly is associated with several comorbidities that may remain unnoticed at the time of diagnosis when treatment of the pituitary adenoma is prioritised (29). In the majority of patients with acromegaly, the CTS symptoms improve after biochemical control of GH excess, even though median nerves of acromegaly patients remain larger compared with matched controls and CTS has previously been reported in $31 \%$ of patients with acromegaly during long-term follow-up (19, 21, $22,30)$. Thus, awareness of the risk for CTS in patients with acromegaly is important even after diagnosis and biochemical control. However, in the current study, only a few cases needed decompression surgery for CTS after their acromegaly diagnosis, which indicates that the diagnosis and treatment of acromegaly decrease the risk of CTS.

Female gender and diabetes are known risk factors for CTS in the general population $(16,31,32,33)$. Women have a smaller carpal arch, which makes the median nerve more vulnerable to compression neuropathy (34). In addition, altered oestrogen levels may play a role in the pathophysiology of CTS in women (35). However, previous smaller studies did not show any effect of gender or diabetes mellitus on the risk of CTS in patients with acromegaly $(22,36)$. This large nationwide study is the first to show that female gender is an independent risk factor for CTS in patients with acromegaly. Thus, the gender difference for CTS observed in the general population appears to be preserved in acromegaly, as acromegaly increases the risk for CTS to the same extent in men and women. In line with previous reports, we did not find diabetes mellitus to further increase the risk for CTS in patients with acromegaly (35). Previous studies suggest that disease duration and biochemical activity of acromegaly might be risk factors for CTS $(22,25,30,36)$. Biochemical activity could not be formally investigated in the current study due to the lack of biochemical data.

The long diagnostic delay in acromegaly, which has not improved sufficiently in recent decades, has created an interest for acromegaly screening in groups of patients with acromegaly-related comorbidities $(4,13,37,38,39)$. The diagnostic delay appears to be longer in women with acromegaly who present with more advanced disease at the time of diagnosis (40). The current findings that CTS before the diagnosis of acromegaly is 6-times more common in patients with acromegaly than in the general population together with a mean latency period from CTS diagnosis to acromegaly diagnosis of 3 years indicate a possibility to shorten the time to acromegaly diagnosis in patients with CTS, especially in women considering the female predominance of this comorbidity. However, in a study attempting to screen for acromegaly in 196 patients with CTS using a short questionnaire and serum insulinlike growth factor-1 level, no patients with acromegaly were found (41). Considering the low incidence of acromegaly, larger studies are needed to determine if there is any potential for acromegaly screening in patients with CTS.

The finding that CTS is 4-times more frequent in patients with acromegaly during the whole study period is 
in line with a previous case-control study showing an odds ratio of 4.3 (42). There is a small risk for underestimation of CTS in acromegaly in our study considering the investigated time-window up to 8.5 years before acromegaly diagnosis and a previous study reporting that CTS occurred on average 6 years before the diagnosis of acromegaly (29). Previous studies have reported a higher incidence of CTS in acromegaly, which most likely reflects that our data included only patients with confirmed CTS in specialised care (i.e. orthopaedic or hand surgery departments) $(19,20,21,25,29)$. Thus, patients with milder CTS may not have been included, that is, those not receiving an ICD-10 diagnosis code within specialised care or not requiring CTS surgery. However, our SIR analyses accurately reflect the excess risk of CTS in patients with acromegaly since the registry data on CTS diagnosis and surgery is equal for the acromegaly cohort and the general Swedish population. In addition, the retrospective study design may potentially introduce, at least in theory, a selection bias as patients with acromegaly and CTS may be more likely to be correctly diagnosed with acromegaly compared with patients without CTS. Since our incidence of CTS is in line with or below previously reported figures in acromegaly and considering the long follow-up in the present study (8020 person-years), we believe that this potential bias has little or no effect on our results $(13,19$, 21, 29).

This is the first nationwide study investigating CTS in a large unselected cohort of patients with acromegaly with the consequent advantage of analysing solid registry data on CTS diagnosis and surgery in both patients with acromegaly and in the general Swedish population. Collection of longitudinal registry data enabled investigation of the temporal relation of CTS and acromegaly during a long period of time. The Patient Registry has a good coverage and high validity offering high quality of data at a national level (26). The diagnosis of CTS has high reliability as it was mainly made at orthopaedic or hand surgery departments and the majority of patients with CTS have undergone CTS surgery.

\section{Conclusions}

Patients with acromegaly have a six-fold increased risk for CTS before the diagnosis of acromegaly compared with the general population. More than eight out of ten patients with acromegaly and CTS were diagnosed and surgically treated for CTS prior to the diagnosis of acromegaly. This creates a diagnostic time window when vigilance for signs of acromegaly and CTS might contribute to an earlier diagnosis of acromegaly, especially in women.

\section{Supplementary materials}

This is linked to the online version of the paper at https://doi.org/10.1530/ EJE-20-0530.

\section{Declaration of interest}

D S O has received consultancy fees from Novo Nordisk, Pfizer, Ipsen and Sandoz, and unrestricted research grants from Sandoz. D E has received lecture fees from Ipsen. O R has received lecture fees from Novo Nordisk, Ipsen, Sandoz and Pfizer, an unrestricted research grant from HRA Pharma, and consultancy fees from Novartis, Alnylam and HRA Pharma. D G is employee of PharmaLex. The remaining authors have no conflicts of interest declare.

\section{Funding}

The study was financed by grants from the Swedish state under the agreement between the Swedish government and the county councils (the ALF agreement), a private donation for pituitary research to Umeå University and scholarships from the Emil Andersson's fund and the J C Kempe's foundation.

\section{Acknowledgements}

The authors wish to thank The National Board of Health and Welfare for excellent collaboration. The authors are grateful to the statisticians Anders Pehrsson and Mattias Molin of the Statistiska Konsultgruppen (Gothenburg, Sweden) for performing all the statistical analyses in the study. They also would like to thank Peter Todd (Tajut Ltd., Kaiapoi, New Zealand) for third-party writing assistance in drafting of this manuscript, for which he received financial compensation from ALF funding.

\section{References}

1 Melmed S. Acromegaly. New England Journal of Medicine 2006355 2558-2573. (https://doi.org/10.1056/NEJMra062453)

2 Dal J, Feldt-Rasmussen U, Andersen M, Kristensen LØ, Laurberg P, Pedersen L, Dekkers OM, Sørensen HT \& Jørgensen JO. Acromegaly incidence, prevalence, complications and long-term prognosis: a nationwide cohort study. European Journal of Endocrinology $2016 \mathbf{1 7 5}$ 181-190. (https://doi.org/10.1530/EJE-16-0117)

3 Colao A, Ferone D, Marzullo P \& Lombardi G. Systemic complications of acromegaly: epidemiology, pathogenesis, and management. Endocrine Reviews 200425 102-152. (https://doi. org/10.1210/er.2002-0022)

4 Katznelson L, Laws Jr ER, Melmed S, Molitch ME, Murad MH, Utz A, Wass JA \& Endocrine Society. Acromegaly: an endocrine society clinical practice guideline. Journal of Clinical Endocrinology and Metabolism 201499 3933-3951. (https://doi.org/10.1210/jc.20142700)

5 Lesén E, Granfeldt D, Houchard A, Dinet J, Berthon A, Olsson DS, Björholt I \& Johannsson G. Comorbidities, treatment patterns and cost-of-illness of acromegaly in Sweden: a register-linkage population-based study. European Journal of Endocrinology 2017176 203-212. (https://doi.org/10.1530/EJE-16-0623)

6 Vouzouneraki K, Franklin KA, Forsgren M, Wärn M, Persson JT, Wik H, Dahlgren C, Nilsson AS, Alkebro C, Burman P et al. Temporal 
relationship of sleep apnea and acromegaly: a nationwide study. Endocrine 201862 456-463. (https://doi.org/10.1007/s12020-0181694-1)

7 Esposito D, Ragnarsson O, Granfeldt D, Marlow T, Johannsson G \& Olsson DS. Decreasing mortality and changes in treatment patterns in patients with acromegaly from a nationwide study. European Journal of Endocrinology 2018178 459-469. (https://doi.org/10.1530/ EJE-18-0015)

8 Ritvonen E, Löyttyniemi E, Jaatinen P, Ebeling T, Moilanen L, Nuutila P, Kauppinen-Mäkelin R \& Schalin-Jäntti C. Mortality in acromegaly: a 20-year follow-up study. Endocrine-Related Cancer 2016 23 469-480. (https://doi.org/10.1530/ERC-16-0106)

9 Keskin FE, Yetkin DO, Ozkaya HM, Haliloglu O, Sadri S, Gazioglu N, Tanrıver N, Ak H, Hatipoglu E \& Kadıoglu P. The problem of unrecognized acromegaly: surgeries patients undergo prior to diagnosis of acromegaly. Journal of Endocrinological Investigation 2015 38 695-700. (https://doi.org/10.1007/s40618-015-0245-3)

10 Siegel S, Streetz-van der Werf C, Schott JS, Nolte K, Karges W \& Kreitschmann-Andermahr I. Diagnostic delay is associated with psychosocial impairment in acromegaly. Pituitary 201316 507-514. (https://doi.org/10.1007/s11102-012-0447-z)

11 Holdaway IM, Rajasoorya RC \& Gamble GD. Factors influencing mortality in acromegaly. Journal of Clinical Endocrinology and Metabolism 200489 667-674. (https://doi.org/10.1210/jc.2003031199)

12 Abreu A, Tovar AP, Castellanos R, Valenzuela A, Giraldo CM, Pinedo AC, Guerrero DP, Barrera CA, Franco HI, Ribeiro-Oliveira Jr A et al. Challenges in the diagnosis and management of acromegaly: a focus on comorbidities. Pituitary 201619 448-457. (https://doi. org/10.1007/s11102-016-0725-2)

13 Esposito D, Ragnarsson O, Johannsson G \& Olsson DS. Prolonged diagnostic delay in acromegaly is associated with increased morbidity and mortality. European Journal of Endocrinology 2020182 523-531. (https://doi.org/10.1530/EJE-20-0019)

14 Giustina A, Barkan A, Beckers A, Biermasz N, Biller BMK, Boguszewski C, Bolanowski M, Bonert V, Bronstein MD Casaneuva FF et al. A consensus on the diagnosis and treatment of acromegaly comorbidities: an update. Journal of Clinical Endocrinology and Metabolism 2020105 dgz096. (https://doi.org/10.1210/clinem/ dgz096)

15 Atroshi I, Gummesson C, Johnsson R, Ornstein E, Ranstam J \& Rosén I. Prevalence of carpal tunnel syndrome in a general population. JAMA 1999282 153-158. (https://doi.org/10.1001/ jama.282.2.153)

16 Padua L, Coraci D, Erra C, Pazzaglia C, Paolasso I, Loreti C, Caliandro P, Hobson-Webb LD. Carpal tunnel syndrome: clinical features, diagnosis, and management. Lancet Neurology 201615 1273-1284. (https://doi.org/10.1016/S1474-4422(16)30231-9)

17 Küçükakkaş O \& Yurdakul OV. The diagnostic value of clinical examinations when diagnosing carpal tunnel syndrome assisted by nerve conduction studies. Journal of Clinical Neuroscience 201961 136-141. (https://doi.org/10.1016/j.jocn.2018.10.106)

18 Duckworth AD, Jenkins PJ \& McEachan JE. Diagnosing carpal tunnel syndrome. Journal of Hand Surgery 201439 1403-1407. (https://doi. org/10.1016/j.jhsa.2014.03.039)

19 Baum H, Lüdecke DK \& Herrmann HD. Carpal tunnel syndrome and acromegaly. Acta Neurochirurgica 198683 54-55. (https://doi. org/10.1007/BF01420508)

20 Kameyama S, Tanaka R, Hasegawa A, Tamura T \& Kuroki M. Subclinical carpal tunnel syndrome in acromegaly. Neurologia Medico-Chirurgica 199333 547-551. (https://doi.org/10.2176/ nmc.33.547)

21 Miller A, Doll H, David J \& Wass J. Impact of musculoskeletal disease on quality of life in long-standing acromegaly. European Journal of Endocrinology 2008158 587-593. (https://doi.org/10.1530/EJE-070838)
22 Sasagawa Y, Tachibana O, Doai M, Tonami H \& Iizuka H. Median nerve conduction studies and wrist magnetic resonance imaging in acromegalic patients with carpal tunnel syndrome. Pituitary 201518 695-700. (https://doi.org/10.1007/s11102-015-0642-9)

23 Mestron A, Webb SM, Astorga R, Benito P, Catala M, Gaztambide S, Gomez JM, Halperin I, Lucas-Morante T, Moreno B et al. Epidemiology, clinical characteristics, outcome, morbidity and mortality in acromegaly based on the Spanish Acromegaly Registry (Registro Espanol de Acromegalia, REA). European Journal of Endocrinology 2004151 439-446. (https://doi.org/10.1530/ eje.0.1510439)

24 Oktayoglu P, Nas K, Kilinç F, Tasdemir N, Bozkurt M \& Yildiz I. Assessment of the presence of carpal tunnel syndrome in patients with diabetes mellitus, hypothyroidism and acromegaly. Journal of Clinical and Diagnostic Research 20159 OC14-OC18. (https://doi. org/10.7860/JCDR/2015/13149.6101)

25 Tagliafico A, Resmini E, Nizzo R, Bianchi F, Minuto F, Ferone D \& Martinoli C. Ultrasound measurement of median and ulnar nerve cross-sectional area in acromegaly. Journal of Clinical Endocrinology and Metabolism 200893 905-909. (https://doi.org/10.1210/jc.2007-1719)

26 Ludvigsson JF, Andersson E, Ekbom A, Feychting M, Kim JL, Reuterwall C, Heurgren M \& Olausson PO. External review and validation of the Swedish national inpatient register. BMC Public Health 201111 450. (https://doi.org/10.1186/1471-2458-11-450)

27 Wettermark B, Hammar N, MichaelFored C, Leimanis A, Otterblad Olausson P, Bergman U, Persson I, Sundström A, Westerholm B \& Rosén M. The new Swedish Prescribed Drug Register: opportunities for pharmacoepidemiological research and experience from the first six months. Pharmacoepidemiology and Drug Safety 200716 726-735. (https://doi.org/10.1002/pds.1294)

28 Socialstyrelsen. Klassifikation av Vårdåtgärder (KVÅ). Stockholm: Socialstyrelsen, 2018. (available at: https://www.socialstyrelsen.se/ utveckla-verksamhet/e-halsa/klassificering-och-koder/kva/). Accessed on 30 Apr 2020.

29 Caron P, Brue T, Raverot G, Tabarin A, Cailleux A, Delemer B, Renoult PP, Houchard A, Elaraki F \& Chanson P. Signs and symptoms of acromegaly at diagnosis: the physician's and the patient's perspectives in the ACRO-POLIS Study. Endocrine 201963 120-129. (https://doi.org/10.1007/s12020-018-1764-4)

30 Resmini E, Tagliafico A, Nizzo R, Bianchi F, Minuto F, Derchi L, Marinoli C \& Ferone D. Ultrasound of peripheral nerves in acromegaly: changes at 1-year follow-up. Clinical Endocrinology 2009 71 220-225. (https://doi.org/10.1111/j.1365-2265.2008.03468.x)

31 Atroshi I, Englund M, Turkiewicz A, Tägil M \& Petersson IF. Incidence of physician-diagnosed carpal tunnel syndrome in the general population. Archives of Internal Medicine 2011171 943-944. (https:// doi.org/10.1001/archinternmed.2011.203)

32 Pourmemari MH \& Shiri R. Diabetes as a risk factor for carpal tunnel syndrome: a systematic review and meta-analysis. Diabetic Medicine 201633 10-16. (https://doi.org/10.1111/dme.12855)

33 Tseng C-H, Liao C-C, Kuo C-M, Sung F-C, Hsieh DPH \& Tsai C-H. Medical and non-medical correlates of carpal tunnel syndrome in a Taiwan cohort of one million. European Journal of Neurology 201219 91-97. (https://doi.org/10.1111/j.1468-1331.2011.03440.x)

34 Lakshminarayanan K, Shah R \& Li ZM. Sex-related differences in carpal arch morphology. PLoS ONE 201914 e0217425. (https://doi. org/10.1371/journal.pone.0217425)

35 Al-Rousan T, Sparks JA, Pettinger M et al. Menopausal hormone therapy and the incidence of carpal tunnel syndrome in postmenopausal women: findings from the Women's Health Initiative. PLoS ONE 2018 13 e0207509. (https://doi.org/10.1371/journal.pone.0207509)

36 Alibas H, Gogas Yavuz D, Kahraman Koytak P, Uygur M, Tanridag T \& Uluc K. Peripheral nervous system assessment in acromegaly patients under somatostatin analogue therapy. Journal of Endocrinological Investigation 201740 33-40. (https://doi.org/10.1007/s40618-0160522-9) 
37 Reid TJ, Post KD, Bruce JN, Nabi Kanibir M, Reyes-Vidal CM \& Freda PU. Features at diagnosis of 324 patients with acromegaly did not change from 1981 to 2006: acromegaly remains underrecognized and under-diagnosed. Clinical Endocrinology 201072 203-208. (https://doi.org/10.1111/j.1365-2265.2009.03626.x)

38 Danilowicz K, Fainstein Day P, Manavela MP, Herrera CJ, Deheza ML, Isaac G, Juri A, Katz D \& Bruno OD. Implementing a screening program for acromegaly in Latin America: necessity versus feasibility. Pituitary 201619 370-374. (https://doi.org/10.1007/s11102-0160714-5)

39 Boguszewski CL. Acromegaly: 'you must know it to think of it'. European Journal of Endocrinology 2020183 C1-C4. (https://doi. org/10.1530/EJE-20-0281)
40 Lenders NF, McCormack AI \& Ho KKY. Management of endocrine disease. Does gender matter in the management of acromegaly? European Journal of Endocrinology 2020182 R67-R82. (https://doi. org/10.1530/EJE-19-1023)

41 Zoicas F, Kleindienst A, Mayr B, Buchfelder M, Megele R \& Schöfl C. Screening for acromegaly in patients with carpal tunnel syndrome: a prospective study (ACROCARP). Hormone and Metabolic Research 2016 48 452-456. (https://doi.org/10.1055/s-0042-100913)

42 Prencipe N, Floriani I, Guaraldi F, Di Giacomo SV, Cannavo S, Arnaldi G, Berton A, Torri V, Spinello M, Arvat E et al. ACROSCORE: a new and simple tool for the diagnosis of acromegaly, a rare and underdiagnosed disease. Clinical Endocrinology 201684 380-385. (https://doi.org/10.1111/cen.12959)

Received 15 May 2020

Revised version received 02 September 2020

Accepted 29 October 2020 